\title{
O COMPATIBILISMO INCOMPATIBILISTA DE KANT: A LIBERDADE NOS INTERSTÍCIOS DO DETERMINISMO
}

\author{
[KANT'S INCOMPATIBILIST INCOMPATIBILISM: THE FREEDOM THROUGH WAYS OF DETERMINISM
}

RESUMO: O presente artigo pretende delinear o compatibilismo incompatibilista de Kant. Kant defende, além da compatibilidade da liberdade com o determinismo, a compatibilidade do compatibilismo com o incompatibilismo. Embora seja comum, a discussão a respeito do caráter compatibilista ou incompatibilista, em sentido excludente, é improdutiva e fadada ao fracasso. A solução kantiana implica a famosa e problemática teoria dos dois mundos. Somos cidadãos de dois mundos ou atribuimos dois significados ao mundo no qual estamos imersos? A solubilidade do problema da acomodação entre a liberdade e o determinismo demandou uma profunda transformação no conceito de racionalidade. A racionalidade kantiana é teórica, prática, estética e teleológica e cada dimensão discursiva apresenta principios diversos e condições de legitimidade diferentes. A categoria hermenêutica Ubergang [passagem] favorece a compreensão do trânsito discursivo entre as várias dimensões da racionalidade. Conceitos-chave assumem significados diferentes em perspectivas distintas da racionalidade. Ignorar a racionalidade complexa conduz inevitavelmente à aporia e ao paradoxo.

Palavras-Chave: Kant; Liberdade; Compatibilismo; Incompatibilismo;
ABstract: The present article intends to outline Kant's incompatibilism compatibilism. Kant defends, besides the compatibility of freedom with determinism, the compatibility of compatibilism with incompatibilism. Although commonplace, the discussion regarding the character of compatibilism or incompatibilism in an exclusionary sense is unproductive and doomed to failure. The Kantian solution implies the famous and problematic two-world theory. Are we citizens of two worlds or do we attribute two meanings to the world in which we are immersed? The solubility of the problem of accommodation between freedom and determinism demanded a profound transformation in the concept of rationality. Kantian rationality is theoretical, practical, aesthetic and teleological and each discursive dimension presents different principles and different conditions of legitimacy. The hermeneutic category Übergang [passage] favours the understanding of the discursive transit between the various dimensions of rationality. Key concepts are taken in different meanings in different perspectives of rationality. Ignoring complex rationality inevitably leads to aporia and paradox.

KEYwORDS: Kant; Freedom; Compatibilism; Incompatibilism; Complex rationality

Racionalidade complexa

escopo desse artigo é investigar o modo como Kant relacionou liberdade e
determinismo. Com respeito ao modo como se relaciona liberdade e determinismo, os filósofos são classificados geralmente como compatibilistas ou como incompatibilistas. Os compatibilistas defendem que a ação humana é determinada sem que isso comprometa a liberdade e a imputabilidade. Os incompatibilistas, por sua vez,

* Doutor em Filosofia pela Universidade de Coimbra, Portugal. Mestre em Filosofia pelo Ateneo Pontificio Regina Apostolorum de Roma. Licenciado em Filosofia pela Faculdade Batista Brasileira. Bacharel em Teologia pelo Instituto de Ciências Religiosas. E-mail: freirefranz@gmail.com 
sustentam que o determinismo exclui a liberdade e a imputabilidade. (WOOD, 1998, p. 239). Kant defende, além da compatibilidade da liberdade com o determinismo, a compatibilidade do compatibilismo com o incompatibilismo. Embora seja comum, a discussão a respeito do caráter compatibilista (ROSEFELDT, 2012; LANGSAM, 2000) ou incompatibilista (BOJANOWSKI, 2012; ALLISON, 1990) em sentido excludente, da doutrina da liberdade kantiana é improdutiva e fadada ao fracasso. A liberdade é interpretada a partir de duas perspectivas: a fenomênica (cosmológica) e a numênica (ação moral). Desde a perspectiva cosmológica, Kant é indubitavelmente compatibilista. "Assim se encontrariam, simultaneamente, no mesmo ato e sem qualquer conflito, a liberdade e a natureza, cada uma em seu significado pleno, conforme se referissem à sua causa inteligível ou à sua causa sensível" (KrV, A 541/B 569). Por outro lado, desde a perspectiva da ação, Kant defende o incompatibilismo, ao opor de modo inequívoco mecanismo natural e liberdade.

Kant compartilha com os filósofos modernos a tentativa de alojar as estruturas fundamentais do querer nos interstícios do determinismo. A solução kantiana representada na teoria dos dois mundos [o mundus phaenomenon e o mundus intelligibilis] é problemática tanto sob o ponto de vista teórico quanto sob o ponto de vista prático. O conceito de liberdade, anunciado solenemente como o "fecho de abóbada de todo o edifício de um sistema da razão pura" (KpV, A 4), está eivado de aporias. Embora Kant afirme que "para além do campo da experiência possível, não pode haver princípios sintéticos a priori” (KrV, A 248/B 305), a liberdade é conhecida através da lei moral, juízo sintético a priori prático, dado além do campo da experiência possivel. Em face do determinismo, a liberdade assume conotações diversas, nem sempre facilmente reconduzíveis a interesses sistemáticos.

Sem obliterar o caráter aporético, defende-se que a solução hermenêutica se encontra no reconhecimento do caráter pluridimensional da racionalidade kantiana. À procura de uma redefinição para o homem, no contexto do novo paradigma introduzido pela revolução científica, Kant empreendeu uma profunda transformação no conceito de racionalidade. Kant institui a racionalidade complexa e procedural como crítica à noção tradicional (eminentemente substancial) de racionalidade. A racionalidade kantiana é teórica, prática, estética e teleológica e cada dimensão discursiva apresenta princípios diversos e condições de legitimidade diferentes. A melhor forma de defender o indubitável caráter sistemático da reflexão sobre a liberdade é o reconhecimento das diversas dimensões da racionalidade kantiana e a acomodação das aporias nas transições entre os modos discursivos da racionalidade complexa. Kant transita entre as variadas modalidades discursivas; por vezes, ele retoma ideias e conceitos desde outro ponto de vista sem fazer uma referência explícita a essa mudança de perspectiva. Ao longo do artigo, constata-se essa sinuosidade discursiva, de tal forma que uma abordagem monolítica (ou seja, feita desde uma única perspectiva da racionalidade) resulta desde o início fadada ao fracasso. O reconhecimento dessas transições [Übergang], permite a articulação semântica dos vários significados da liberdade em sua relação com o determinismo.

Dada a complexidade da razão kantiana - teórica, prática, estética e teleológica -, a liberdade (assim como outros conceitos fundamentais) assume um caráter polissêmico. Trata-se de discursos que não se completam (pois não são discursos de uma mesma perspectiva da racionalidade), nem se contradizem; antes, complementam-se sistematicamente. A investigação levará em conta o interesse sistemático de Kant: fundamentar a possibilidade de juízos sintéticos a priori teóricos, práticos, estéticos e teleológicos. Assumir-se-á, como princípio hermenêutico, a afirmação de Kant no prefácio à segunda edição da Crítica da razão pura: "qualquer exposição filosófica está sujeita a ter pontos fracos (pois não pode ter armadura tão resistente como a da 
exposição matemática), sem que, todavia, a estrutura do sistema, considerada na sua unidade, corra perigo" (KrV, B XLIV).

\section{LABIRINTO DO DETERMINISMO}

Desde a consolidação da visão mecanicista e matematizada do universo, tornouse necessária a reconstrução do conceito de liberdade. Os filósofos que a defenderam, tiveram de reconciliá-la com a descrição científica do mundo. O mecanicismo da física newtoniana, ao representar matematicamente o cosmos e prever estados futuros ou retrodizer estados passados, corroborou a tese de que o universo é determinado por uma complexa cadeia de relações causais estritamente necessárias. A geometrização do universo não foi assumida apenas como um aporte metodológico, ela assume a posição de fundamento metafísico, que descarta todo princípio teleológico. O mecanicismo vê confirmada a antiga suspeita determinista, intimamente vinculada à noção de destino ou fatalidade, de que as ações humanas estariam, assim como todo o mundo físico, sujeitas à necessidade causal. Todos os pensamentos, sentimentos e mecanismos psicológicos seriam invariavelmente pré-determinados e absolutamente previsíveis segundo nexos causais estritos e compulsórios. Consequentemente, o sentimento de decisão e influência sobre as próprias ações não seria mais que uma ilusão cognitiva. Dito de outra maneira, a pessoa não poderia agir de outra forma, ainda que conservasse um sentimento de influxo autônomo e de opção dentre várias alternativas. Num mundo plenamente determinado, causalidade determinada e vontade se identificam. Nesse caso, o indeterminismo não apenas contraria os fatos, mas alijaria a vontade (causalidade) da teoria da ação moral. A liberdade não encontraria lugar nem no determinismo, nem no indeterminismo.

Kant se insere na tradição compatibilista. Hobbes, Locke e Hume são os mais importantes expoentes de um compatibilismo mecânico: "A liberdade e a necessidade são compatíveis, o que ocorre com a água que não tem apenas a liberdade, mas também a necessidade de descer pelo canal, também ocorre com as ações que os homens voluntariamente praticam" (HOBBES, 2003, p. 181). A teoria da ação é inserida na semântica da necessidade mecânica como um elemento mais na cadeia de causalidade. Toda a natureza - inclusive as ações humanas - são governadas somente pelas leis do movimento. "Tudo o que é produzido é produzido necessariamente, pois tudo o que é produzido tem uma causa suficiente que o produziu; e, portanto, também as ações voluntárias são necessitadas" (HOBBES, 1999, p. 38). Sob a influência do modelo mecanicista, reduziram o problema do livre arbítrio ao problema da livre ação, fundando a tendência consolidada, também entre os autores contemporâneos, de tratar a expressão "problema do livre arbitrio" como título meramente honorifico para o problema da livre ação. Concebem a ideia de liberdade como pertencendo ao sujeito agente, ou seja, àquele que tem o poder de agir ou deixar de agir, e jamais à volição. O famoso problema da liberdade da vontade, considerado capital para a imputabilidade humana por grande parte da tradição filosófica, é considerado inapropriado, ininteligível, irracional e absurdo: "a liberdade refere-se tão pouco à vontade como a rapidez do movimento ao sono, ou a quadratura à virtude" (LOCKE, 1999, p. 222). Não há alternativa anterior à volição. Querer é querer algo. Enquanto algo não é querido, não há volição. Há uma efetiva coincidência entre a faculdade de querer e a representação de algo querido. Então, uma pessoa agiria de modo diverso somente se fossem outras as condições causais envolvidas na ação. A pessoa é responsável, não por dispor de alternativas, mas porque há um vínculo causal necessário entre a ação realizada e o caráter de sua vontade. Hume (2001, p. 440) adverte sobre a confusão entre espontaneidade e liberdade de indiferença. A espontaneidade opõe-se à violência, a liberdade de 
indiferença significa uma negação da necessidade e das causas. Esses autores cosmologizam a noção de liberdade, entendendo-a como espontaneidade e autonomia. As noções de espontaneidade e autonomia não comportam a necessidade de alternativa. A escolha espontânea pode estar condicionada por profundos, complexos e inconscientes determinantes biológicos, psicológicos e histórico-sociais. Ademais, a ausência de condicionamentos intrinsecos ou introjetados não exclui a possibilidade de escolhermos a única alternativa efetivamente possivel. A liberdade não é uma ideia que pertence à vontade ou preferência e não implica a necessidade de alternativas. A libertas indifferentiae, entendida como ausência de determinação da vontade, é considerada pelos compatibilistas como inconciliável com as noções de causalidade e necessidade vigentes no paradigma mecanicista e matematizado do universo.

Leibniz não pôde admitir que a liberdade fosse pensada nos termos meramente mecânicos com que Hobbes a associa ao fluxo da água. O universo autômato é regido por um princípio espiritual que explica o movimento dotado de finalidade, o que extrapola o princípio de inércia que rege os corpos. Coube a Leibniz rechaçar a redução do problema do livre arbítrio ao problema da livre ação. Leibniz pretende conciliar a rejeição da libertas indifferentiae com a afirmação de que o arbítrio é livre. Ele atribui à liberdade três características fundamentais: inteligência, espontaneidade e contingência (LEIBNIZ, 2017, p. 338). A centralidade da inteligência no conceito de liberdade implica a desconexão da semântica mecanicista. $\mathrm{O}$ automatismo que rege a realidade e as opções humanas é de natureza espiritual e tem caráter teleológico. Leibniz se esforça para demonstrar que a razão inclina sem necessitar. Por isso, os longos argumentos em função da contingência tanto para os conteúdos do entendimento divino quanto para os decretos da vontade criadora. A contingência leibniziana não visa à dissolução do automatismo sobre o qual o compatibilismo é alicerçado. Basta que a contingência assegure o mínimo necessário à teleologia. O homem leibniziano, representado na tensão entre a necessidade e a contingência, é definido como autômato espiritual (LEIBNIZ, 2017, p. 164-165). O autômato opera como uma enteléquia, por necessidade hipotética (LEIBNIZ, 2004, p. 134). Leibniz adota a distinção de Bramhall entre necessidade absoluta e necessidade hipotética. A necessidade hipotética significa que suposta a causa, o efeito se segue. A necessidade absoluta, por sua vez, implica que o evento, ou a ação efetuada, era necessário antes da concorrência das causas que o determinam (BRAMHALL, 1999, p. 52). Ele entende que Hobbes não foi capaz de superar o necessitarismo por não caracterizar como distintos os âmbitos de jurisdição, embora universais, dos princípios de contradição e de razão suficiente. Por isso, tampouco distinguiria entre necessidade metafísica, dotada de caráter geométrico e aplicável apenas às verdades de razão, e a necessidade hipotética, aplicada à física e à moral. Enquanto o princípio de contradição se aplica ao entendimento, o princípio de razão suficiente presume o ato voluntário (LEIBNIZ, 2007, p.264).

Kant, assim como Leibniz, intenciona combinar a rejeição da libertas indifferentiae com a defesa da liberdade no âmbito do arbítrio. $\mathrm{O}$ automatismo espiritual, adotado por Leibniz como solução, é rejeitado por Kant (KpV, A 181) ${ }^{1}$. No entanto, na Analítica Transcendental, Kant admite como princípio infalível o encadeamento universal de todos os fenômenos no tempo. As ações humanas são inseridas no nexo causal natural com previsibilidade semelhante aos fatos da natureza (KpV, A 177-178). As palavras de Kant parecem uma rendição ao determinismo natural: "visto que o tempo passado não está mais em meu poder, cada ação que pratico tem que ser necessária mediante fundamentos determinantes que não estão em meu poder, isto é, jamais sou livre no momento em que ajo" (KpV, A 169). A possibilidade da liberdade, examinada na terceira antinomia, presume a inviolabilidade e a prioridade gnosiológica do determinismo no horizonte da natureza. Trata-se somente de saber se é possivel uma 
liberdade compatibilizada com o determinismo.

Já se nos depara a dificuldade de saber se a liberdade em geral será possível e, no caso afirmativo, se poderá coexistir com a universalidade da lei natural da causalidade; ou seja, por conseguinte, se se trata de uma proposição verdadeiramente disjuntiva como esta: todo o efeito no mundo deve ser proveniente ou da natureza ou da liberdade, ou se não poderão ambas verificar-se simultaneamente, num mesmo acontecimento, em diferente perspectiva. A exatidão daquele enunciado, respeitante ao encadeamento universal de todos os acontecimentos do mundo sensivel, de acordo com leis naturais imutáveis, já está estabelecida como um princípio da analítica transcendental e não comporta exceção. Trata-se, pois, somente de saber se, apesar deste princípio, em relação a este mesmo efeito determinado pela natureza, se pode verificar também a liberdade ou se esta é completamente excluída por essa regra inviolável. (KrV, A 536/ B564)

Tendo em vista a presunção da irrefutabilidade do princípio determinístico, a possibilidade de uma liberdade incompatibilista no âmbito da natureza, expressa numa proposição disjuntiva ["todo o efeito no mundo deve ser proveniente ou da natureza ou da liberdade"], é meramente retórica. Sob a égide do paradigma científico do mundo não há lugar para a liberdade incompatibilista no âmbito da natureza. A única possibilidade é a adoção de um axioma representado por uma sentença conectiva: "poderão ambas (causas) verificar-se simultaneamente, num mesmo acontecimento, em diferente perspectiva". Essa afirmação tem significado ambíguo, pois há na primeira crítica duas abordagens concernentes ao significado da relação entre o mundus phaenomenon e o mundus intelligibilis. Essa ambiguidade repercute na interpretação sobre o conceito de liberdade.

Numa abordagem ontológica, Kant concilia determinismo e liberdade afirmando a possibilidade de um mesmo efeito implicar simultaneamente duas causas, a fenomênica e a numênica. Na terceira antinomia, visando a acomodar a liberdade e o determinismo, Kant propõe que os fundamentos da inconciliação entre a tese e a antítese são ilusórios. O defensor da tese assevera que, além da causalidade natural, deve-se admitir a liberdade como uma causalidade integrada à ordem dos fenômenos $(\mathrm{KrV}, \mathrm{A}$ 444/B 472). O proponente da antítese, por sua vez, sustenta que não se pode admitir a possibilidade da liberdade na ordem dos fenômenos, pois nesse caso dar-se-ia o rompimento da ordem causal natural ( $\mathrm{KrV}$, A 445/B 473). Kant resume o conflito entre as partes como um confronto entre o conhecimento teórico e o interesse prático $(\mathrm{KrV}, \mathrm{A}$ 466-468/B 494-496). A tese implicaria uma contradição de legalidades no âmbito fenomênico. Nesse contexto, a liberdade representaria uma negação da legalidade natural, um acaso, exatamente conforme o argumento de Hume; o que sem dúvida afetaria a possibilidade de um conhecimento certo. A antítese, por sua vez, ao refutar a possibilidade de coexistência da liberdade com a legalidade natural no plano fenomênico, extirparia toda moralidade e ofenderia a interesses práticos. A solução kantiana implica a idealização da liberdade num sentido transcendental, ou seja, causalidade incausada, extrafenomênica, definida como a capacidade de iniciar por si um estado de coisas e considerada a condição de possibilidade da moralidade e da imputabilidade moral (KrV, A 533/B 561). Por tal conceito de liberdade ficariam refutadas tanto a tese quanto a antítese em sua pretensão absoluta e excludente.

Importa também à compreensão do método de análise kantiano, entender a forma como Kant aborda as antinomias. Enquanto as primeiras são antinomias matemáticas, nas quais tanto a tese quanto a antítese são consideradas falsas; a terceira e a quarta antinomia são dinâmicas, tanto a tese quanto a antítese podem ser consideradas verdadeiras. A diferença entre as antinomias matemáticas e as dinâmicas se refere ao modo como se dá o regresso do condicionado à condição. Nas antinomias matemáticas, 
o condicionado e suas condições são sempre homogêneos, isto é, todos são membros da mesma série espaciotemporal. Portanto, conclui-se que a série tem um número finito ou infinito de membros, o que significa que as teses em disputa são contraditórias. No caso da terceira antinomia - assim como da quarta - trata-se de um regresso do efeito à causa ou fundamento. Nesse caso, os elementos podem, mas não necessitam, ser homogêneos, pois é possível conceber um fundamento que não pertença à série dos fenômenos, tratando-se então de um fundamento inteligivel. A tese da terceira antinomia pode ser interpretada também dessa forma, ao passo que a antitese só elimina a possibilidade de tal caso no mundo fenomênico. Logo, mantém-se a possibilidade de que ambas proposições estejam corretas: a tese com a afirmação de uma primeira causa inteligível, livre em sentido transcendental, e a antitese que rejeita a possibilidade de tal causalidade na série fenomênica (ALLISON, 2004, p. 312). A filosofia crítico-transcendental implica restrições epistêmicas, que vetam a metafísica - e seus objetos: Deus, a liberdade e a imortalidade - no âmbito da razão teórica ( $\mathrm{KrV}$, A 337/B 395, nota). Na esfera teórica, embora pensável e possível, a liberdade tem um sentido estritamente negativo $\mathrm{e}$ problemático (KrV, A 433/B 461). Na medida em que não comporta a possibilidade de intuição sensível, a liberdade é um ens rationalis, isto é, um nada de fenomenalidade (KrV, A 290-291 /B 347-348). O númeno em sentido positivo só poderia ocorrer numa intuição intelectual, o que não nos é possível (KrV, A 253-254/B 307-309). Nesse caso, a liberdade é uma ideia, algo pensável e possível como fundamento numênico, pois não contém contradição, mas cuja realidade e efetividade não se podem demonstrar. Isto é, é pensável e possível que sob a perspectiva inteligível, a ação seja livre em sentido incompatibilista e, sob a perspectiva fenomênica, a ação livre esteja compatibilizada com o nexo causal natural.

Com base nesses pressupostos, Beck defende uma interpretação ontológica como solução para a terceira antinomia.

A solução do problema resultante de provas da verdade de duas proposições que se contradizem entre si ele encontrou na sua famosa "teoria dos dois mundos". De acordo com isso, há um mundo fenomênico, no qual cada mudança é determinada por uma anterior no espaço e no tempo; e um mundo numênico, que não é espacial e temporal, e do qual o mundo fenomênico é apenas uma aparência para mentes constituídas como a nossa. A causalidade livre no interior do mundo numênico e entre o mundo fenomênico e numênico pode ser pensada sem contradição, mas somente a causalidade temporal relacionada a eventos e estados no mundo fenomênico pode ser conhecida. Não há contradição, porque a causalidade livre e a causalidade natural são predicadas de tipos de seres ontologicamente distintos. (BECK, 1987, p. 41)

Essa abordagem não é isenta de problemas. A solução da Dialética, ao definir a liberdade como causalidade numênica em oposição à causalidade natural, combinada às teorias defendidas na Analítica, mantém a liberdade transcendental como uma ideia problemática, dotada de valor meramente regulativo, sem vigor constitutivo. A afirmação de um mesmo efeito para duas causas - a numênica e a fenomênica - impõe o problema da efetividade da liberdade e da validade do dever. Que sentido tem o imperativo categórico se não é possível romper o nexo de encadeamento causal natural? Em que sentido o efeito da liberdade coincide com o efeito das leis naturais imutáveis?

Numa abordagem metodológica ou semântica, o mundus intelligibilis não é mais que o conceito universal de um mundo em geral, "em que se abstrai de todas as condições da intuição do mesmo e em relação ao qual não é possível, portanto, nenhuma proposição sintética, nem afirmativa nem negativa" (KrV, A 433/B 461). Haveria uma única realidade ontológica, da qual o númeno e o fenômeno são apenas "pontos de vista" [Standpunkt] (KrV, A 536/B 564; B XXVI-XXVII; A 38/B 55; A 808/B 836; A433/ 
B 461). No prólogo da Crítica da Razão Pura, a distinção entre fenômeno e coisa em si é apresentada como um método hermenêutico pelo qual se evita a contradição entre o determinismo e a liberdade. Um mesmo objeto é dotado de dupla significação (zweierlei Bedeutung). O mesmo objeto pode ser referido a uma intuição sensível, sob certas condições subjetivas, que impõem ao objeto representado uma série de condições formais, ou pensado independentemente de tais relações subjetivas, numa representação puramente indeterminada, como coisa em si mesma ( $\mathrm{KrV}, \mathrm{B}$ XXVI). Na Crítica da Faculdade do Juízo, no capitulo sobre a "Dialética da Faculdade de Juizo Teleológica", particularmente do parágrafo 69 até o 78, Kant trabalha a distinção entre a faculdade de juízo reflexiva e a faculdade de júzo determinante. $O$ fundamento da distinção reside no fato de a faculdade de juizo reflexiva não possuir nenhum fundamento especial na causalidade, acrescentando, somente para o uso da razão, outra espécie de investigação diferente daquela que é conduzida segundo leis mecânicas, para completar a insuficiência destas. O reconhecimento de uma economia, providência, beneficência ou artífice inteligente (Werkmeister) não seria mais que a indicação de "uma espécie de causalidade da natureza, segundo uma analogia com nossa razão no uso técnico, para ter presente a regra pela qual têm de ser investigados certos produtos da natureza" (KU, AA 5: 383). A causalidade numênica, espontânea, é pensada como exterior à natureza, como princípio forasteiro, no entanto, condição indispensável para pensar algum fundamento (KU, AA 5: 381). No contexto desta análise, Kant conclui, de modo ainda mais contundente, que a causalidade numênica não se encontra na natureza, mas deve ser pensada necessariamente como princípio heurístico. Desta forma, Kant identifica a categoria da causalidade, tanto numênica quanto fenomênica, com princípios explicativos que não podem ser tomados como princípios dogmáticos e constitutivos numa e mesma coisa, pois um tipo de explicação excluiria o outro (KU, AA 5: 411-412). Nesse caso, o conceito de liberdade pode ser interpretado como uma categoria meramente regulativa, útil para fins heuristicos, destituído de qualquer referência ontológica (KrV, B XXVII). Diante disso, não apenas a efetividade, mas a própria realidade da liberdade é posta em suspeição. Essa interpretação é reforçada pelo uso de expressões como "pontos de vista" (Standpunkt) e de verbos como "pensar" (denken) e "considerar" (ansehen):

Mas ainda nos resta uma saída, que é procurar se, quando nós nos pensamos (denken), pela liberdade, como causas eficientes a priori, não adoptamos outro ponto de vista (anderer Standpunkt) do que quando nos representamos a nós mesmos, segundo as nossas ações, como efeitos que vemos diante dos nossos olhos. (GMS, AA 4: 450)

Por tudo isto é que um ser racional deve considerar-se (ansehen) a si mesmo, como inteligência (portanto não pelo lado das suas forças inferiores), não como pertencendo ao mundo sensível, mas como pertencendo ao mundo inteligível; tem por conseguinte dois pontos de vista (zwei Standpunkte) dos quais pode considerar-se a si mesmo e reconhecer leis do uso das suas forças, e portanto de todas as suas ações: o primeiro, enquanto pertence ao mundo sensível, sob leis naturais (heteronomia); o segundo, como pertencente ao mundo inteligível, sob leis que, independentes da natureza, não são empíricas, mas fundadas somente na razão. (GMS, AA 4: 452)

Ao longo das últimas décadas, sob o influxo da chamada interpretação epistemológica, discutiu-se a validade da clássica interpretação ontológica da doutrina crítica. Autores como Gerold Prauss e Henry Allison defenderam que, ao invés de pensar dois mundos ontologicamente distintos, o mundo sensível e o mundo inteligível, Kant distinguiu dois aspectos - o sensível e o inteligível - num mesmo mundo. 
Fundamentados na negatividade conceitual da noção de coisa em si (númeno e mundo moral) e na abordagem metodológica deste conceito, importantes autores negam realidade à coisa em si e ao mundo inteligivel. Na verdade, Prauss e Allison retomam o antigo problema da afecção. O problema surgiu logo entre os primeiros intérpretes da Crítica da Razão Pura. Jacobi, Reinhold, Schulze e Fichte reagiram à afirmação da coisa em si e de um mundo numênico na Crítica da Razão Pura como uma contradição inaceitável no sistema kantiano. Em 1787, mesmo ano da publicação da segunda edição da Crítica da Razão Pura, Friedrich Heinrich Jacobi publica David Hume über den Glauben, oder Idealismus und Realismus, Ein Gespräch. Jacobi conclui que Kant recai numa aporia: sem a pressuposição de um elemento externo na origem das sensações, não seria possível ao kantismo explicar a construção do conhecimento; por outro lado, a pressuposição de coisas em si afetantes da sensibilidade contraria os fundamentos do idealismo transcendental. Harold Arthur Prichard (1909, p. 72) e Peter Frederick Strawson $(1995$, p. 34) elaboraram críticas vigorosas à dualidade fenômeno-coisa em si, considerando-a viciada e capaz de tornar inviável qualquer conhecimento humano, pois tanto o fenômeno é aparência, quanto a coisa em si é incognoscível.

Para Prauss, a confusão entre a acepção empírica e a transcendental da "coisa em si" e do "fenômeno" conduz a sérias dificuldades hermenêuticas (PRAUSS, 1989, p. 4950). Prauss entende que os críticos ignoram as diferentes acepções aplicadas por Kant a tais termos, imputando às expressões uma significação metafísico-transcendente (transzendent-metaphysisch). As "coisas em si" (e o númeno) seriam quase-objetos de um mundo inteligivel por detrás do mundo sensivel dos fenômenos. A consequência mais grave seria a reificação da "coisa em si". O núcleo do argumento de Gerold Prauss se refere à distinção entre o sentido empírico e o sentido transcendental das categorias "coisa em si" e "fenômeno". Considerando desde uma perspectiva empírica, pode-se afirmar que existem coisas em si mesmas, que provocam as modificações subjetivas, ou representações, que experimentamos. Nesse caso, a "coisa em si" e o "fenômeno" referem-se a entidades essencial e numericamente diversas: o objeto, eventualmente físico, e as representações por eles provocadas. Considerando desde uma perspectiva transcendental, no entanto, a "coisa em si" e o "fenômeno" se referem ao mesmo objeto físico, a partir de modos diversos de consideração. O objeto é tomado como fenômeno enquanto está submetido às condições da sensibilidade e do entendimento e é considerado como "coisa em si" ou não fenômeno na medida em que se abstrai de tais condições fenomênicas (PRAUSS, 1989, p. 44). A "coisa em si” não possui significado substantivo, mas adverbial de modo. Ou seja, a "coisa em si" possui acepção meramente negativa, pois trata-se da consideração de algo abstraindo sua condição fenomênica (PRAUSS, 1989, p. 136). Portanto, a relação entre os conceitos de "fenômeno" e "coisa em si" é de dependência analítica. Ou seja, os dois modos de consideração seriam dois momentos reflexivos indissociáveis sobre uma mesma entidade (objeto empírico). Primeiro as entidades empíricas são consideradas como fenômenos, dados empíricos submetidos às condições da sensibilidade e do entendimento. Somente num segundo momento é possível considerar essas mesmas entidades independentemente de tais condições (PRAUSS, 1989, p. 93). Por isso, Prauss conclui que antes da "coisa em si" ser a condição do fenômeno, o fenômeno é a condição da "coisa em si". Ocorre, pois, uma inversão se comparamos ao modo empírico de leitura do "fenômeno" e da "coisa em si" (PRAUSS, 1989, p. 39).

Tendo em vista uma defesa do idealismo kantiano, Allison propõe o conceito de "condição epistêmica", pela qual seriam superados os problemas originados por uma interpretação ontológica.

Por condição epistêmica entende-se aqui a condição necessária para a representação de objetos, ou seja, a condição sem a qual nossas representações não 
se relacionariam com objetos ou, equivalentemente, possuem realidade objetiva. Dessa forma, poderia também ser denominado "condição objetivadora", pois cumpre uma função objetivadora. Como condição de possibilidade da representação de objetos, as condições epistêmicas são distintas tanto das condições psicológicas quanto das condições ontológicas. Pelas primeiras entendese uma propensão ou mecanismo da mente, que rege a crença e a aquisição de crenças. O costume ou hábito de Hume é um excelente exemplo de tal condição. Pelas últimas entende-se a condição de possibilidade da existência das coisas, que condicionam estas coisas de forma completamente independente da sua relação com a mente humana (ou qualquer outra mente). O espaço e o tempo absolutos de Newton são condições nesse sentido. As condições epistêmicas compartilham com as primeiras a propriedade de serem "subjetivas", isto é, refletem a estrutura e as operações da mente humana. As condições epistêmicas diferem das condições psicológicas devido à sua função objetivadora. Correlativamente, as condições epistêmicas compartilham com os últimos a propriedade de serem objetivas ou objetivadoras. No entanto, diferem porque as condições epistêmicas condicionam a objetividade de nossas representações das coisas ao invés da própria existência das coisas mesmas. Como veremos, o problema fundamental que enfrenta o idealismo transcendental é explicar como tais condições podem ser subjetivas e objetivas ou objetivadoras ao mesmo tempo. (ALLISON, 2004, p. 11)

Desde a perspectiva teórica, Kant delineia um conceito negativo de liberdade, identificado com a espontaneidade, entendida como capacidade de iniciar por si, fora do tempo, uma série causal independente do nexo causal natural ( $\mathrm{KrV}$ A 533/ B 561). Na teologia, a atemporalidade se identifica com a eternidade e é aplicável somente a Deus. Não cabe nesse artigo uma análise sobre o controverso significado da condição atemporal do homem ou como seja possível que um ser atemporal (estaria na eternidade?) produza ações no tempo. Basta-nos salientar que a solução kantiana para o problema da liberdade seria insustentável se não for possível conceber uma noção coerente de atemporalidade ou uma razoável descrição do modo como um ser atemporal age no tempo. O conceito de liberdade como "absoluta espontaneidade" é fundamento autêntico da imputabilidade" da ação moral (KrV A 448/B 476). No entanto, não oferece qualquer referência normativa, limitando-se à afirmação da capacidade de ser causa incausada de um determinado estado de coisas. Trata-se de conceito similar ao primeiro motor em sentido aristotélico, de uma causalidade através da liberdade, possibilidade de uma natureza suprassensível, completamente independente da lei dos eventos no mundo sensorial (BECK, 1960, p. 184). Kant reconheceu a fragilidade do conceito negativo de liberdade, ao admitir ser "infecunda para conhecer a sua essência" (GMS AA 4: 446) e conduzir-nos inevitavelmente ao embaraço especulativo e ao desinteresse prático (KrV A 475/B 503). No entanto, é preciso esclarecer que o conceito negativo de liberdade não é uma excrescência. A liberdade de espontaneidade é o único resultado possível no âmbito da terceira antinomia da razão pura. É o modo pelo qual Kant pode assegurar a possibilidade de realidade objetiva à liberdade, ainda que seu conteúdo conceitual tenha de permanecer indeterminado para a filosofia especulativa. Para Prauss, o conceito de liberdade é negativo em duplo sentido.

Por um lado, do ponto de vista da legalidade da natureza, só pode ser considerada ilegal ou anarquista, como já referido. Por outro lado, deve também permanecer negativo, no sentido de que apenas permite ser mostrado: é, de fato, concebível como uma capacidade independente da natureza, ou seja, por um conceito que não está em contradição nem em si mesmo nem com a natureza; mas isto não torna essa capacidade reconhecível, razão pela qual o seu conceito é uma mera ideia: permanece aberto se o seu objeto existe ou não, isto é, se a liberdade como faculdade realmente existe ou não. (PRAUSS, 1983, p. 64) 


\section{A REALIDADE E EFETIVIDADE DA CAUSALIDADE NUMÊNICA}

Desde o ponto de vista especulativo, a solubilidade do problema da acomodação entre a liberdade e o determinismo apresenta-se prima facie insolúvel. No prefácio da Crítica da Razão Pura, Kant adverte que o objetivo central do projeto crítico é estabelecer os limites do conhecimento como método para a afirmação da realidade e efetividade dos conteúdos da fé racional ( $\mathrm{KrV}$, B XXX). Somente no âmbito da racionalidade prática é possível descrever, além do conceito positivo de liberdade, a realidade e efetividade da causalidade numênica. As tentativas de interpretação que ignorem a perspectiva hermenêutica da racionalidade complexa, dificilmente sairão do labirindo do determinismo. A razão kantiana é pluridimensional - teórica, prática, estética e teleológica - e apresenta princípios diversos e condições de legitimidade diferentes para cada dimensão discursiva. A unidade da razão depende da articulação de suas diversas dimensões. Lehmann (1969) e Terra (2003) defendem a adoção da categoria "passagem" (Übergang) como chave hermenêutica para a correta compreensão do movimento oscilatório da reflexão kantiana, dotada de um momento sistemático e outro aporético. Nesse sentido, pela Übergang é possível a construção de um conceito diferenciado de "unidade sistemática". Terra empreende uma análise sobre o emprego do termo Übergang e conclui que ele tem incidência frequente e relevante desde a Crítica da Razão Pura para demarcar a passagem de um assunto a outro e até de uma perspectiva analítica para outra. Salienta o emprego do termo na Fundamentação da Metafísica dos Costumes para articular as três seções (TERRA, 2003, p. 60-61). Contudo, o termo Übergang/Überschritt assume uma conotação técnica a partir da Primeira Introdução à Crítica do Juízo (EEKU, AA 20: 246). A passagem (Übergang) significa a articulação entre os diversos momentos da racionalidade. Dessa forma, a própria Crítica do Juízo é uma Übergang entre a metafísica da natureza e a metafísica da liberdade. O sistema da metafísica se mantém com duas partes, enquanto o da crítica passa a ter três (TERRA, 2003, p. 58). A "passagem" assume uma conotação hermenêutica cada vez mais robusta e relevante, alcançando sua maior amplitude e sistematização na Opus Postumum (OP, AA 21: 17).

É particularmente importante para a pesquisa que empreendemos a "passagem" da razão teórica para a razão prática. No prefácio da Crítica da Razão Prática, Kant se refere à passagem que justifica o reexame, sob a perspectiva da racionalidade prática, de ideias e conceitos já analisados na primeira critica. Os conceitos de liberdade, causalidade, experiência e conhecimento são ressignificados ao serem retomados no âmbito prático da racionalidade.

Basta isso para justificar por que, nesta obra, os conceitos e proposições fundamentais da razão especulativa pura, que já sofreram sua crítica particular, são aqui às vezes submetidos de novo à prova, o que, aliás, não convém muito ao curso sistemático de uma ciência a ser constituída (já que coisas ajuizadas, justamente, só têm que ser referidas e não ser de novo discutidas), o que, porém, aqui era permitido e mesmo necessário; porque com aqueles conceitos a razão é considerada em trânsito (im Übergange) para um uso totalmente diferente do que ela lá fez deles. Semelhante trânsito (Übergang), porém, torna necessária uma comparação do uso antigo com o novo para distinguir bem a nova via da anterior e, ao mesmo tempo, permitir observar a sua interconexão. (KpV, A 11-12)

Para descrever a realidade e efetividade da causalidade numênica, faz-se necessário ressaltar a conexão entre a lei moral e a sensibilidade. A experiência pela qual o sentido prático de liberdade confirmaria o seu sentido transcendental não cabe nos limites da Crítica da Razão Pura. Kant lida, no âmbito da primeira crítica, com um conceito de experiência estritamente cognitivo. Na verdade, o conceito de filosofia 
transcendental, apresentado logo no prefácio à segunda edição da primeira crítica, é tão estreito que não comporta os princípios e conceitos fundamentais da moralidade $(\mathrm{KrV}, \mathrm{A}$ 15/B 29). O componente empírico da moralidade é considerado bastardo e jamais assimilado pela filosofia transcendental ( $\mathrm{KrV}$, A 802/B 830, nota). Por isso, a liberdade é considerada uma questão concernente à psicologia, embora deva ser resolvida pela filosofia transcendental (KrV, A 535/B 563). Evidencia-se que, na Crítica da Razão Pura, a filosofia transcendental coincide integralmente com a razão teórica.

Apesar dos limites inerentes ao estreito conceito de filosofia transcendental no âmbito da primeira crítica, Kant aponta para um horizonte de experiência humana não redutível à experiência cognitiva. O homem é "uma das causas da natureza cuja causalidade deve estar submetida a leis empíricas". Logo, sua causalidade deve ter "também carácter empírico como todas as outras coisas da natureza". Contudo, o homem se destaca dos demais seres porque "se conhece além disso a si mesmo pela simples apercepção e, na verdade, em atos e determinações internas que não pode, de modo algum, incluir nas impressões dos sentidos". Por um lado, o homem é fenômeno. Por outro, é dotado de caráter inteligível, "porque a sua ação não pode de maneira nenhuma atribuir-se à receptividade da sensibilidade" (KrV, A 546-547/B 574-575). O termo caráter refere-se à "lei da sua causalidade, sem a qual não seria uma causa" (KrV, A 539/B 567). A alusão a atos e determinações internas não contidos na receptividade da sensibilidade traz à luz, ainda na primeira crítica, a questão sobre um modo específico de receptividade para a moralidade. Kant indica a necessidade de definir o âmbito da experiência sobre o qual apoiar a validade de juízos sintéticos a priori práticos. É preciso descrever o modo como a causalidade da razão pura prática afeta a sensibilidade na experiência do dever, que "exprime uma espécie de necessidade e de ligação com fundamentos que não ocorre em outra parte em toda a natureza" (KrV, A 546-547/B 574-575). Kant apresenta já na primeira crítica a absoluta consciência de que o fato moral demandava uma noção sui generis de receptividade.

O factum é uma experiência genuinamente moral, que atesta a realidade objetiva - o que não envolve nenhuma dedução ou esforço da razão teórica - e o potencial constitutivo da racionalidade prática. Somente a partir da Fundamentação da Metafísica dos Costumes Kant formula de modo inequívoco a relação entre a motivação racional e a sensibilidade. Para que o homem, simultaneamente racional e afetado pelos sentidos, possa querer racionalmente como dever é "preciso sem dúvida uma faculdade da razão que inspire um sentimento de prazer ou de satisfação no cumprimento do dever, e, por conseguinte, que haja uma causalidade da razão que determine a sensibilidade conforme aos seus princípios". A ocorrência, na qual "um simples pensamento, que não contém em si nada de sensível, pode produzir uma sensação de prazer ou de dor" não é cognoscível a priori, logo, "a respeito da qual temos de consultar só a experiência" (GMS, AA 4: 460).

Na Crítica da Razão Prática, Kant descreve essa receptividade da lei moral como factum da razão, ou seja, ocorrência que antecede toda a argumentação sobre a sua possibilidade ou sobre as consequências dela decorrentes. Considerados os princípios do sistema kantiano, a razão prática deve partir de proposições fundamentais, dados elementares, fundamentos primários de toda ciência e não se originar dela. Kant insiste na imediatez do fato, demonstrado no "uso prático mais comum da razão" (KpV, A 163). Kant argumenta em favor dessa imediatez apelando para exemplos que assinalam a experiência moral, experiência da lei moral, como o desvelamento da liberdade. De outro modo, "jamais se teria chegado à façanha de introduzir a liberdade na ciência, se a lei moral, e com ela a razão prática, não tivesse sobrevindo e impingido a nós esse conceito. Mas também a experiência confirma essa ordem dos conceitos em nós" (KpV, A 54). 
Por meio do factum chega-se ao conceito positivo da liberdade. Nas obras fundacionais do sistema ético, a liberdade e a lei moral se identificam como expressão da razão pura prática. A liberdade, causalidade numênica, é definida como ratio essendi, "condição da lei moral" e a lei é ratio cognoscendi da liberdade (KpV, A 5). Por outro lado, identifica-se a necessidade natural com a heteronomia das causas eficientes. Ocorre um contraste irredutivel entre natureza e liberdade, isto é, entre o fenomênico e o numênico. Disso resulta que "vontade livre e vontade submetida a leis morais são uma e a mesma coisa" (GMS, AA 4: 446-447). A liberdade, enquanto causalidade da razão pura prática, é a condição de possibilidade da praticidade ou objetividade moral. O que não se harmoniza com os fundamentos racionais da liberdade, não é praticamente objetivo. A liberdade é faculdade para agir a priori (Refl, AA 19: 288). A ação da liberdade segundo sua legalidade determina a sensibilidade pelo sentimento do dever. Por isso, a lei moral é "a consciência de si de uma razão prática pura, mas esta totalmente idêntica ao conceito positivo de liberdade" (KpV, A 52-53).

Na Crítica da Razão Prática, o factum é caracterizado como uma espécie de sensação (Art von Empfindung) produzida unicamente pela legislação da razão prática. Se a atividade da razão produz uma sensação, é preciso admitir uma receptividade pura, essencialmente diversa da receptividade da sensibilidade. Kant elabora o conceito de receptividade pura como um análogo da noção de receptividade da sensibilidade: assim como as máximas empíricas se dão a conhecer pelo sentimento de prazer ou de dor, a máxima moral se dá a conhecer no respeito. Na Metafísica dos Costumes, Kant confirma a importância da dimensão estética na teoria da ação moral e opõe o sentimento moral e afecção patológica: “o estado estético (a afecção do sentido interno) é, pois, um sentimento ou patológico ou moral. O primeiro é aquele sentimento que precede a representação da lei, o último, aquele que apenas pode se seguir a esta" (MS, AA 6: 399). Descrição similar é feita na Crítica da Razão Prática, na qual Kant novamente apresenta a lei moral como um momento estético posterior ao da sensibilidade e em franca heterogeneidade. Enquanto o fundamento determinante da sensibilidade é o sentimento de prazer ou de dor; o fundamento determinante da racionalidade é "uma peculiar espécie de sensação, que, porém, não precede a legislação da razão prática mas, muito antes, é produzida unicamente por ela e, na verdade, como uma coerção, ou seja, pelo sentimento de um respeito" (KpV, A 164-165). A heterogeneidade do fundamento da razão pura prática torna-se plenamente cognoscivel na resistência contra toda a mescla de inclinação, de tal meneira que mesmo o entendimento humano mais comum é capaz de reconhecê-la.

A teoria do factum tem a função de esclarecer e justificar os juízos sintéticos a priori "segundo a pureza de sua origem, mesmo no juízo dessa razão comum" (KpV, A 163). A consciência do imperativo categórico como fato da razão justifica o imperativo categórico em sua validade absoluta. A consciência da lei como resistência da razão experiência de um conflito de motivos, devido à heterogeneidade dos fundamentos atribui justificação à convicção da realidade do uso sintético da razão pura prática e dissipa a suspeita de que a liberdade seja uma "ideia quimérica" [chimärische Idee] (GMS, AA 4: 445). A teoria do fato não faz apelo a algo exterior ou à dedução, a nenhum fato empírico, mas à atividade que produz "o único factum da razão pura, que deste modo se proclama como originariamente legislativa [sic volo, sic jubeo]" (KpV, A 56). Nesse sentido, os famosos exemplos da forca (KpV, A 54) e do depósito (KpV, A 49) sublinham, além da imediatez, o vigor e o valor do fato da razão (manifestação da liberdade), mesmo quando entra em jogo o forte instinto de autopreservação.

A expressão Factum der Vernunft refere-se à receptividade pura da lei pelo sentimento de respeito em relação à coercitividade do imperativo categórico. Diverso do Faktum, o Factum significa imputatio facti, ou seja, o âmbito no qual as ações se dão 
sob a ideia de liberdade, sob um mandamento ou proibição (GMS AA 4: 448). Cada factum é meritum ou demeritum, nenhum é adiaphoron. O factum é produto da atividade legislativa da razão visando à ação como meio para um efeito (KpV, A 37). A atividade da razão manifesta no factum assegura consistência e realidade "para um objeto suprassensivel da categoria de causalidade, a saber, da liberdade" (KpV, A 9). O factum define o âmbito no qual o homem é necessariamente imputável, pois age sob a ideia de liberdade, mesmo que não atue pela causalidade numênica.

Poder-se-ia levantar uma certa hesitação em torno da compreensão do factum. Por um lado, Kant afirma que a razão prática legislativa se dá, "tão cognoscível" e "tão excelsa" por meio de "uma espécie de sensação" produzida pela legislação da razão prática (KpV, A 164). Por outro lado, a lei moral é "inequivocamente dada", mas que "não é nenhum fato empírico" (KpV, A 56). Kant está consciente de todas as limitações analógicas que o termo "fato" - além dos termos "experiência" e "estético" - comporta. Kant reconhece: "a coisa é bastante estranha e não tem equivalente em todo o restante conhecimento prático" (KpV, A 55). O factum da razão é considerado inegável (KpV, A 56); "pois, se ela, enquanto razão pura, é efetivamente prática, prova a sua realidade e a dos seus conceitos pelo ato e toda a arguição dessa possibilidade é vã" (KpV, A 3). No entanto, Kant aplica o atributo restritivo "como se fosse" (gleichsam) ao termo factum em quatro das onze passagens em que o vocábulo aparece (KpV, A 81. 96. 163. 187). Supõe-se que Kant entenda que o uso do termo é legitimo, apesar dos riscos de má interpretação implicados. É imprescindivel observar que Kant afirma que a lei não é um fato empírico; no entanto, declara a existência de "fundamentos empíricos" do querer racional (KpV, A 164).

Dessa forma, o factum atesta que o domínio inteligível é, exclusivamente por este caso, mais amplo que o domínio do fato empírico (experiência cognitiva). De fato, na analitica da razão prática pura, mais precisamente na "Elucidação crítica da analítica da razão prática pura", Kant traça um paralelo sistemático entre a razão prática e a razão teórica e afirma que ambas "têm como fundamento a mesma faculdade de conhecer", "na medida em que ambas são teóricas". A analítica da razão teórica ocupa-se do conhecimento dos objetos dados ao entendimento e tinha de começar na intuição, pela sensibilidade, para então, ir até os conceitos. A analítica da razão prática segue a trajetória inversa, pois a razão prática "não se ocupa com objetos para conhecê-los, mas com a sua própria faculdade de (conformemente ao seu conhecimento) torná-los efetivos" por meio da causalidade da vontade. A razão deve conter o fundamento de determinação da vontade, de tal forma que não pode indicar nenhum objeto da intuição, mas "indicar somente uma lei da intuição" (KpV, A 159-160). Diante da clareza das afirmações de Kant não parece uma interpretação aceitável a afirmação de Allison de que o fato "não conta como experiência no sentido técnico de Kant" (ALLISON, 2004, p. 318). Na verdade, melhor seria dizer que não se trata de experiência em sentido cognitivo. Embora Kant aborde a noção de fato com cautela, ela é apresentada como legítima e esclarecedora. A rigor, também o termo "conhecimento" é aplicado em sentido analógico. As condições de cognoscibilidade da ação livre a partir do entendimento são problemáticas. Pode-se remontar até à causa inteligível, isto é, reconhecer que ocorre uma condição incondicionada do ponto de vista dos fenômenos (KrV, A 557/B 585). Mas, Kant reconhece que o conhecimento sobre a moralidade não pode ser considerado absolutamente certo, pois não se pode concluir com segurança que a ação conforme à lei "não tenha sido um impulso secreto do amor-próprio, oculto sob a simples capa daquela ideia, a verdadeira causa determinante da vontade" (GMS, AA 4: 407). Na Lições de Antropologia, registra-se dois meios de acesso ao conhecimento: a razão [Vernunft] e o entendimento [Verstand]. O conhecimento moral se obtém através da razão. 
Muitas coisas são de tal natureza que só podem ser conhecidas com a razão; portanto, não com o entendimento [Viele Dinge sind so beschaffen, daß man sie nur lediglich aus der Vernunft erkennen kann, also nicht durch den Verstand]. Certamente, há muitas coisas que são conhecidas com a razão, mas também com o entendimento a partir da experiência. E, então, os conhecimentos que se obtêm mediante a razão são mais distintos. Sem embargo, há muitas coisas que só podem ser conhecidas mediante a razão. Trata-se daquelas onde a razão aporta ao fundamento a ideia, como por exemplo a virtude [Diese sind solche, wo die Vernunft dem Grunde die Jdee giebt Z. E. die Tugend]. É certo que a experiência nos dá exemplos da virtude, mas devo dispor do conceito para ajuizá-la. Precisa-se da razão para todos os casos do conhecimento em que se pergunta, não como seja algo, mas como deva ser, pois a razão mostra como devem ser as coisas, enquanto a experiência só mostra como são [...] Se um conhecimento sobre as coisas é um modelo segundo o qual se ordena algo, então esse conhecimento é ideia. (V-Anth/ Fried, AA 25: 550-551)

Não obstante o sentimento moral se refira à obrigação (à coercitividade da lei moral), não há obrigação de possuir um sentimento moral ou de adquiri-lo. Toda consciência da obrigação tem como fundamento esse sentimento para tornar-se consciente da necessitação que assenta no conceito de dever. O ser humano, enquanto ser moral, o tem originariamente em si. Tem-se a obrigação de cultivá-lo e fortalecê-lo por meio da admiração de sua origem imperscrutável" (MS, AA 6: 399-400). O sentimento moral é a condição de possibilidade da consciência da lei. A suscetibilidade em relação à lei moral é identificada num sentimento sui generis, genuinamente moral, o respeito. A motivação da razão é sentida no respeito. $\mathrm{O}$ respeito constitui-se no modo especifico pelo qual a lei moral se torna primariamente acessível. Dessa forma, o respeito não é posterior à ação, nem critério de discernimento para a decisão moral, tampouco fundamento. O respeito refere-se à sensibilidade (Sinnlichkeit), "estrutura fundamental da transcendência do si mesmo moral". Heidegger o designa sentimento moral ou sentimento de si mesmo. Tal definição vincula o respeito ao sentimento (Gefühl), distinguindo-o completamente da sensibilidade cognitiva (Sinn) (HEIDEGGER, 2012, § 30).

A heterogeneidade dos fundamentos no factum revela-se como um confronto positivo de forças. Supera-se pela racionalidade prática a noção nulificada de liberdade (e de mundus intelligibilis) obtida através da razão teórica. Na nota sobre a anfibolia dos conceitos da reflexão, no final da analítica transcendental, Kant subordina a oposição entre o ser e o nada ao problema da objetividade em geral. $\mathrm{O}$ esquematismo assume uma função capital na interpretação do ser e do nada (KrV, A 290/B 346). A partir da tábua das categorias, Kant elabora uma tábua do nada (KrV, A 109/B 151). O nada, desde a perspectiva da razão teórica, significa um limite: ou falta de intuição ou falta de conceito. Kant desdobra o nada em quatro tipos: a) o conceito vazio sem objeto - que Kant identifica com o númeno - é o ens rationalis; b) o conceito da falta de um objeto [nihil privativum], como a sombra e o frio; c) a simples forma da intuição sem substância, como seria a pura forma do tempo e a pura forma do espaço [ens imaginarium]; d) o objeto de um conceito que se contradiz a si próprio é nada, porque o conceito nada é o impossível, como a figura retilínea de dois lados [nihil negativum] (KrV, A 290-291 /B 347-348). Não cabe nesse artigo uma ampla e profunda análise lógica e gnosiológica sobre o nada. Basta-nos a constatação de que a liberdade e todo o mundus intelligibilis é, desde a perspectiva da racionalidade teórica, um tipo de nada, isto é, um mero ente de razão.

O caráter positivo da experiência moral é evocado numa nota da Religião nos limites da simples razão, na qual Kant se refere ao argumento desenvolvido no texto pré-crítico de 1763, Ensaio para introduzir em filosofia o conceito de grandeza 
negativa.

Se o bem $=\mathrm{a}$, o seu oposto contraditório é o não bem. Ora este é consequência de uma simples carência de fundamento do bem $=0$, ou então a consequência de um fundamento positivo da sua contrapartida $=-$ a. No último caso, o não bem pode chamar-se igualmente o mal positivo. (Em relação ao prazer e à dor existe um [termo] médio semelhante, de modo que é o prazer $=\mathrm{a}$, a dor $=-\mathrm{a}$, e o estado em que nenhum dos dois é encontrado, a indiferença $=0$ ). Ora se a lei moral não fosse em nós um motivo impulsor do arbítrio seria o bem moral (a consonância do arbítrio com a lei) $=a$, não bem $=0$, sendo este a simples consequência da carência de um motivo impulsor moral $=$ a $\times 0$. Mas a lei moral é em nós motivo impulsor $=$ a; por conseguinte, a falta de consonância do arbítrio com ela $(=0)$ só é possível como consequência de uma determinação realiter oposta do arbitrio, isto é, de uma resistência deste $=-\mathrm{a}$, isto é, só mediante um arbítrio mau; e, portanto, entre uma má e uma boa disposição de ânimo (princípio interno das máximas), segundo a qual se deve igualmente julgar a moralidade da ação, nada há, pois, de intermédio. (RGV, AA 6: 22)

Kant forja a ideia de virtude negativa, concebida através do modelo de oposição real. Kant critica logicismo racionalista de Leibniz, que pretende explicar o mundo pela oposição lógica [principio de contradição]. Leibniz teria intelectualizado os fenômenos, pois tinha em vista apenas "os conceitos e não o seu lugar na intuição, na qual somente os objetos podem ser dados, desatendendo por completo o lugar transcendental desses conceitos" (KrV, A 271/B 327). Leibniz teria desprezado o que Kant chama realitas phaenomena (KrV, A 273/B 329). O demérito não é a simples ausência de mérito, mas o efeito de um princípio antagonista. Não é possivel pensar uma ação neutra, pois a própria omissão, enquanto impede a colocação do bem, é o resultado de uma resistência negativa que se impôs. A noção de grandeza negativa está intrinsecamente ligada à negação da indiferença [adiaphora] moral das ações.

No escrito pré-crítico de 1963, Ensaio para introduzir a noção de grandezas negativas em filosofia, Kant diferencia a oposição lógica da oposição real e explica a noção de "grandeza negativa". No primeiro capítulo, Elucidação do conceito de grandezas negativas em geral, Kant afirma que duas coisas são opostas quando uma anula o que é posto pela outra. Há, então, dois tipos de oposição: a lógica e a real. A oposição lógica tem origem na contradição, ou seja, afirmar e negar contemporaneamente o predicado de uma coisa. O resultado dessa oposição é o nada entendido como nihil negativum irrepraesentabile. Esta oposição é lógica e, pensa Kant, "é a única para a qual até agora se dirigiu a atenção" (NG, $A A$ 2: 171). A oposição real, com a qual Kant identificará o mal moral, também resulta em nada. Visto que na oposição real os dois predicados não são opostos pelo princípio de contradição, o nada é algo representável, nihil privativum repraesentabile. Dessa forma, "as grandezas negativas não são as negações de grandezas, como dá a entender a semelhança da expressão, sendo, antes, algo em si mesmo verdadeiramente positivo, algo que apenas se opõe a outra coisa" (NG, AA 2: 169).

Kant propõe quatro regras fundamentais para a caracterização da ação moral como uma oposição real.

Como demonstração geral serve o seguinte. As determinações conflitantes umas com as outras têm de, primeiro, ser encontradas no mesmo sujeito. Pois, supondose que haja uma determinação numa coisa, e uma outra, não importa qual, numa outra coisa, então daí não se origina oposição efetiva alguma. Segundo, numa oposição real uma das determinações opostas não pode ser o contrário contraditório da outra, pois senão o conflito seria lógico e, como mostrado acima, impossível. Terceiro, uma determinação não pode negar nada senão o que foi posto 
pela outra determinação, pois aí não reside oposição alguma. Quarto, na medida em que estão em conflito uma com a outra, ambas não podem ser negativas, pois senão nenhuma delas poria algo que fosse suprimido pela outra. Por conseguinte, em toda oposição real, os predicados têm de ser ambos positivos, e de tal modo que na conexão no mesmo sujeito as consequências se suprimam reciprocamente. (NG, AA 2: 176)

Partindo da noção de mal como negação, Kant discrimina duas categorias de males: por falta [mala defectus] e por privação [mala privationis] (NG, AA 2: 182). O mala defectus é a negação de um principio ou oposição. $\mathrm{O}$ mala privationis implica uma força positiva que suprime o bem, sendo, portanto, um "bem negativo". O mal por privação pode dar-se de dois modos: oppositio actualis e oppositio potencialis. Enquanto a oppositio actualis se dá no mesmo sujeito, no qual ocorre um conflito de forças; na oppositio potencialis, tais forças somente potencialmente poderiam apresentar conflito. Logo, a realização da liberdade ou nulificação da vontade se dá numa oppositio actualis. Dessa forma, o omitente incorre em meritum negativum, pois abandonando a lei positiva que deveria cumprir, põe uma ação interior real, engendrada por móbiles que tornam possivel a omissão da causalidade da razão pura prática. Portanto, o vício não é uma ausência de virtude inimputável, mas é uma determinação consciente que se opõe a uma lei, pela qual somos responsáveis (NG, AA 2:182-183).

A descrição do factum e da oppositio actualis conferem realidade à possibilidade vislumbrada por Kant na Crítica da Razão Pura.

E não será antes possível, embora todo o efeito no fenômeno exija absolutamente uma ligação com a sua causa, segundo leis da causalidade empírica, que essa causalidade empírica, sem de nenhum modo romper o seu encadeamento com as causas naturais, possa ser todavia o efeito de uma causalidade não empírica, mas sim inteligível? Ou seja, essa causalidade inteligível seria o efeito da ação originária, em relação aos fenômenos, de uma causa que, enquanto tal, não seria fenômeno, mas inteligível mercê desse poder, embora de resto tenha de ser inteiramente incluída no mundo sensível, como elo de uma cadeia natural. ( $\mathrm{KrV}, \mathrm{A}$ 544/B 572)

Kant compatibiliza liberdade e determinismo. E além disso, compatibiliza o compatibilismo e o incompatibilismo. Nossas ações são causalmente determinadas no tempo por nosso caráter empírico, que, por sua vez, é efeito ou "esquema sensivel" (KrV, A553/B581) do caráter inteligível, determinado de modo independentemente das condições empíricas [liberdade de espontaneidade/conceito negativo de liberdade]. A razão pura prática tem causalidade em relação aos fenômenos, pois ela determina segundo sua legalidade [caráter inteligível] o modo de sentir [o sentimento de respeito]. (KrV, A551/B579).

O compatibilismo incompatibilista de Kant só pode ser adequadamente compreendido à luz da revolução no conceito de racionalidade. Os vários discursos sobre a liberdade se coordenam sistematicamente, se admitirmos "passagens" ou "transições" (Übergang) que articulem os diversos tipos de discurso (teórico, prático, estético e teleológico) no sistema kantiano. São, portanto, fadadas ao fracasso as tentativas de interpretação que leem o projeto crítico somente a partir dos princípios de legitimidade da racionalidade teórica. Grande parte das aporias podem ser acomodadas nessas transições discursivas. Poder-se-ia afirmar que interpretação do mundo inteligível como Standpunkt é compatível com a racionalidade teórica, ao passo que a interpretação ontológica só é possível mediante uma compreensão racional do mundo. Evocamos aqui a distinção e complementaridade entre o conhecimento viabilizado por meio do entendimento e aquele que só pode ser obtido através da razão. Não é preciso negar uma das abordagens ou subordinar uma a outra, de modo a suplantar a disparidade e até o 
aparente paradoxo. A liberdade é abordada sob essas diversas perspectivas, em discursos que não se completam (pois não são discursos de uma mesma perspectiva da racionalidade), nem se contradizem; antes, complementam-se sistematicamente.

\section{REFERÊNCIAS}

ALLISON, Henry. Kant's Theory of Freedom. Cambridge: Cambridge University Press, 1990.

ALLISON, Henry. Kant's Transcendental Idealism. London: Yale University Press, 2004.

BECK, Lewis White. A Commentary on Kant's Critique of Practical Reason. London: The University of Chicago Press, 1960.

ALLISON, Henry. Five concepts of freedom in Kant. In Srzednick, J. T. J.; Korner, Stephan. Philosophical Analysis and Reconstruction. Dordrecht: Martinus Nijhoff Publishers, 1987, p. 35-51.

BOJANOWSKI, Jochen. Ist Kant ein Kompatibilist? In: Sind wir Bürger zweier Welten?: Freiheit und moralische Verantwortung im transzendentalen Idealismus. Hamburg: Mainer, 2012. p. 59-76.

BRAMHALL, John. A Defence of True Liberty. In: HOBBES, Thomas; BRAMHALL, John. Hobbes and Bramhall on Liberty and Necessity. Edited by Vere Chappel. Massachusetts: Cambridge University Press, 1999. p. 43-68.

HEIDEGGER, Martin. Kant y el Problema de la Metafísica. Traducción de Gred Ibscher Roth. México: Fondo de Cultura Económica, 2012.

HOBBES, Thomas. Leviatã ou matéria, forma e poder de uma república eclesiástica e civil. Tradução: João Paulo Monteiro e Maria Beatriz Nizza da Silva. São Paulo: Martins Fontes, 2003.

HOBBES, Thomas. Of Liberty and Necessity. In: HOBBES, Thomas; BRAMHALL, John. Hobbes and Bramhall on Liberty and Necessity. Edited by Vere Chappel. Massachusetts: Cambridge University Press, 1999. pp. 1-14.

HUME, David. Tratado da Natureza Humana. Uma tentativa de introduzir o método experimental de raciocínio nos assuntos morais. Tradução: Déborah Danowsk. São Paulo: Editora Unesp, 2009.

KANT, Immanuel. Kants Gesammelte Schriften. Herausgegeben von der Deutschen Akademie der Wissenschaften, 29v. Berlin: Walter de Gruyter, 1902.

KANT, Immanuel. Crítica da Razão Prática. Tradução, introdução e notas de Valério Rohden. Edição bilíngue. São Paulo: Martins Fontes, 2003.

KANT, Immanuel. Crítica da Razão Pura. Tradução de Manuela Pinto dos Santos e Alexandre Fradique Morujão. Lisboa: Fundação Calouste Gulbenkian, 2001.

KANT, Immanuel. Crítica da Faculdade do Juízo. Tradução de Valério Rohden e António Marques. Rio de Janeiro: Gen e Forense Universitária, 2012.

KANT, Immanuel. Duas introduções à Crítica do Juízo. Tradução de R. Torres Filho. São Paulo: Iluminuras, 1995.

KANT, Immanuel. Ensaio para introduzir a noção de grandezas negativas em filosofia. In: KANT, Escritos Pré-críticos. Tradução de Vinicius Figueiredo e Jair Barboza. São Paulo: Editora UNESP, 2005. pp.51-100.

KANT, Immanuel. Fundamentação da Metafísica dos Costumes. Tradução de Paulo Quintela. Lisboa: Edições 70, 2007.

KANT, Immanuel. Lecciones de Antropología. Fragmentos de estética y antropología. Traducción de Manuel Sanches Rodrígues. Granada: Editorial Comares, 2015.

KANT, Immanuel. Metafísica dos Costumes. Tradução de Clélia Aparecida Martins, Bruno Nadai, Diego Kosbiau e Monique Hulshof. Petrópolis: Editora Vozes, 2013.

KANT, Immanuel. A Religião nos limites da simples razão. Tradução de Artur Morão. Lisboa: Edições 70, 2008.

LANGSAM, Harold. Kant's Compatibilism and his two conceptions of truth. Pacific Philosophical Quarterly. Volume 81, Issue 2, June 2000, p. 164-188.

LEHMANN, G. Das Philosophische Grundproblem in Kants Nachlasswerk. In: zur Geschichte und Interpretation der Philosophie Kants. Berlin: W. de Gruyter, 1969.

LEIBNIZ, Gottfried Wilhelm. Os Princípios da Filosofia ou a Monadologia. In: Discurso de metafísica e outros textos. Tradução de Alexandre da Cruz Bonilha. São Paulo: Martins Fontes, 2004.

LEIBNIZ, Gottfried Wilhelm. Ensaios de teodiceia sobre a bondade de Deus, liberdade do homem 
e a origem do mal. Tradução e notas de Willian Siqueira Piaúi e Juliana Cecci Silva. São Paulo: Estação Liberdade, 2017.

LEIBNIZ, Gottfried Wilhelm. Reflexões sobre a obra que o sr. Hobbes publicou em inglês, sobre a liberdade, a necessidade e o acaso. Trans/Form/Ação, São Paulo, 30(2), 2007, pp. 261272.

LOCKE, John. Ensayo sobre el entendimiento humano. Traducción de Edmundo O'Gorman. México: Fondo de Cultura Económica, 1999.

PRAUSS, Gerold. Kant und das Problem der Dinge an sich. Bonn: Bouvier Verlag, 1989.

PRAUSS, Gerold. Kant über Freiheit als Autonomie. Frankfurt am Main: Klostermann RoteReihe, 1983.

PRICHARD, H. A. Kant's theory of knowledge. Oxford: Clarendon Press. 1909.

ROSEFELDT, Tobias. Kants Kompatibilismus. In: Sind wir Bürger zweier Welten?: Freiheit und moralische Verantwortung im transzendentalen Idealismus. Hamburg: Mainer, 2012. p. 77110.

STRAWSON, Peter F. Los limites del sentido: ensayo sobre la Crítica de la Razón Pura de Kant. Traducción de Carlos Thiebaut Luis-André. Madrid: Ediciones de la Revista de Occidente, 1995.

TERRA, Ricardo. Passagens. Estudos sobre a filosofia de Kant. Rio de Janeiro: Editora UFRJ, 2003.

WOOD, Allen. Kant's Compatibilism. In: KITCHER, Patricia. Kant's Critique of Pure Reason: critical essays. Lanham: Rowman e Littlefield Publishers, 1998. pp. 239-263.

\section{Notas}

1 As obras de Kant serão citadas segundo as normas da Akademie-Ausgabe, conforme a Sociedade Kant Brasileira, disponivel em . A Crítica da Razão Pura será citada segundo as edições A (1781) e B (1789). A Crítica da Razão Prática será citada de acordo com o texto original da primeira edição (1788). A citação será feita na seguinte ordem: abreviatura da obra, número do tomo e número da página. As traduções utilizadas estão referidas na bibliografia. As traduções das demais obras são de minha responsabilidade As siglas usadas no artigo são as seguintes: EEKU - Duas introduções à Crítica do Juízo, GMS - Fundamentação da Metafísica dos Costumes, KpV - Crítica da Razão Prática, KrV - Crítica da Razão Pura, KU - Crítica da Faculdade do Juízo, NG - Ensaio para introduzir a noção de grandezas negativas em filosofia, OP - Opus Postumum, Refl Reflexão, RGV - Religião nos limites da simples razão e V-Anth/Fried - Lições de Antropologia. 